\title{
Inequality in experiences of physics education: Secondary school girls' and boys' perceptions of their physics education and intentions to continue with physics after the age of sixteen
}

\author{
Tamjid Mujtaba ${ }^{1}$ and Michael J. Reiss ${ }^{2}$ \\ Institute of Education, University of London, London, England
}

\begin{abstract}
This paper explores the factors that are associated in England with 15 year-old students' intentions to study physics post-16, when it is no longer compulsory. Survey responses were collated from 5034 year 10 students as learners of physics during the academic year 2008-09 from 137 England secondary schools. Our analysis uses individual items from the survey rather than constructs (aggregates of items) to explore what it is about physics teachers, physics lessons and physics itself that is most correlated with intended participation in physics post-16. Our findings indicate that extrinsic material gain motivation in physics was the most important factor associated with intended participation. In addition, an item-level analysis helped to uncover issues around gender inequality in physics educational experiences which were masked by the use of construct-based analyses. Girls' perceptions of their physics teachers were similar to those of boys on many fronts. However, despite the encouragement individual students receive from their teachers being a key factor associated with aspirations to continue with physics, girls were statistically significantly less likely to receive such encouragement. We also found that girls had less positive experiences of their physics lessons and physics education than did boys.
\end{abstract}

\section{Keywords: Physics; Inequality; Science; Gender; Science education}

\section{Introduction}

The paradox of girls' attainment and participation in higher level physics courses

Within England and many other industrialised countries (e.g. Australia, France, USA) there is a concern in education policy circles about the low rates of progression into further and higher education in the sciences with a recognition, in particular, that females still lag behind males in participation in post-compulsory education physics courses (e.g. Francis, et al., 2003; Hazari et al., 2010; JCQ, 2011a; Bøe et al., 2011). In England, where this study is undertaken, this is despite the fact that since the advent of the National Curriculum in 1989, both males and females have been required to study science (which includes a balance of biology, chemistry and physics, with a small amount of earth science) from age 5 through to age 16, the end of the compulsory phase of education. In 2011 of all examination entries for boys at age 18,6.5\% $(\mathrm{n}=26,011)$ were in Advanced Level physics with the equivalent figure for girls being only $1.5 \%(n=6,849)$. Such findings are despite the fact that interest in science when students are younger is high, with few differences between girls and boys (e.g. Murphy \& Beggs, 2005; Archer et al., in press a).

At the age of 16, students in England take General Certificate of Secondary Education (GCSE) examinations in subjects they have studied for two years. Although students have some choice in which subjects they study for their GCSEs, all such students study English,

Email: t.mujtaba@ioe.ac.uk

Email: m.reiss@ioe.ac.uk 
mathematics and some form of science. However, no subject is compulsory after the age of 16. Most students who remain in full-time education after the age of 16 take Advanced Level (A-Level) courses with A-Level examinations taken at age 18. To be able to study physics at A-Level, students are required to get a high grade (typically $\mathrm{A}^{*}, \mathrm{~A}$ or $\mathrm{B}$, depending on individual establishments' entrance requirements) in GCSE physics or science. The gender gap in progression onto post-compulsory education courses in the sciences is most prominent for physics (JCQ, 2011a), and this has been a problem for many years at secondary school with implicaitons for further education and higher education.

This gender gap in post-compulsory participation in physics is in stark contrast to the attainment levels of girls and boys which are are quite similar. So, for example, in 2011, for GCSE science, $3.0 \%$ of girls achieved the highest grade, $A^{*}$, with only $2.1 \%$ of boys achieving this; $10.1 \%$ of girls obtained a grade $\mathrm{A}$, again compared to a lower percentage of boys (8\%). Similarly, for physics GCSE, $21.7 \%$ of girls and $20.8 \%$ of boys obtained an A* while $27.1 \%$ of girls and $27.4 \%$ of boys obtained an A (JCQ, 2011b).

Masked issues in education equality

Gender inequity in participation rates exist despite industrialised nations passing equality legislation, e.g. DfE (2010) for England. However, in practice there are still established and widely accepted differences in the way many girls and boys experience education. Although there is a recognition that girls are less likely to continue with the sciences, and in particular physics, post-16 there is more of a focus on general patterns of low progression into physics of all students with little policy focus on girls' experiences and the prejudices they encounter within schools and society (Francis \& Skelton, 2005; Archer et. al., in press a) or on social class inequalities (Archer et al., in press b). Our paper will raise issues around poor experiences at school and lower expectations being key factors that are associated with switching girls off from physics. Turning to some of the feminist critiques of education policy and practice we note that there has been a dichotomisation of gender educational issues; girls are increasingly not seen as having problematic issues around schooling whereas boys are seen as having such problems - which moves the debate away from girls' problematic educational experiences (e.g. Francis, 1999; Francis \& Skelton, 2005; Archer \& Francis, 2007). In some of our earlier work on girls' and boys' intended participation in physics post-16 we found that girls, despite often aspiring to study physics after the age of 16, were less likely to be encouraged by their physics/science teachers and families to continue with physics post-16 and were less likely to receive home support for achievement in learning physics (Mujtaba \& Reiss, in press).

Though Mujtaba \& Reiss (in press) and the work presented in this paper do not look at race we recognise that there is a complex interaction between attainment, post-compulsory participation, race, gender and social class, as identified by others (e.g. Archer \& Francis, 2006; Archer \& Francis, 2007). We note the attention that has been given to the recognition that, even in compulsory education, girls' experiences and prioritisations are typically secondary to those of boys (e.g. Paechter, 1998) and are possibly impacted by interactions between class and race. Research has highlighted how working class girls who were assertive and engaged actively with their schooling faced repercussions (Archer et al., 2007). This research demonstrated that the girls used practices such as 'speaking my mind' to generate a sense of worth and identity within educational structures that would have ordinarily have side-lined them. However, the research also found that because such 'assertive' practices were in conflict with the dominant discourses associated with how middle class females behave, this led to conflicts between the working class girls and those in power in their schools - so much so that some girls questioned their own practices. This research also established how parents, teachers and support staff spent disproportionately more time on 
disengaged boys than on girls with girls internalising issues around achievement and blaming themselves for their own low achievement.

The role of teachers in supporting girls' engagement with science was explored in a qualitative study which investigated 11 teachers and 51 Grade 7 and 8 girls from various states across the USA (Buck, 2002). The study found that girls strove to make a connection to science and were able to see the relevance of science in their everyday lives but were largely unable to come across such understandings in their science lessons. The study also revealed that rather than teachers encouraging girls to adapt science concepts to fit in with their own needs and understanding of science, teachers encouraged girls to fit into existing structures already in place in science education - which are not girl-orientated and thus can lead to pushing girls' interests away from science. This point was emphasised some two decades ago by Harding (1991) who reported that an overemphasis on one way of viewing the world affects the ways in which people learn to understand the world. Such a point has also been emphasised by others; science will never open up to the voices of those not traditionally involved in the sciences if science classrooms continue to engage with students using methods put together only through the lens of 'White Western males' (e.g. Reiss, 1993; Mayberry, 1998).

\section{Subject choice and occupational progression}

Research back in the 1980s suggested that girls held gender-specific stereotypes about the sorts of careers they could have (e.g. Spender, 1982). In more recent decades there has been an encouraging shift in the views girls hold about career choice (e.g. Francis, 2000a); girls' aspirations for their future careers are less likely to exclude traditionally male subjects and more girls have higher aspirations than in the 1980s (e.g. Francis, 2000b, 2002). Our own survey work in 137 English schools, specifically focusing on physics choice amongst fifteen year olds, suggests that there are a considerable number of girls who see the value of having a post-16 physics qualification for their future careers (Mujtaba \& Reiss, in press) though such girls still report feeling less encouraged to continue with physics post-16 and state that they receive less support in their physics learning than boys. Survey work conducted with 14 to 16 year-olds in eight English schools in a different study demonstrated that despite a shift in stereotypical attitudes in career choices these still remain. Furthermore, such choices are not a result of mixed-sex schooling or the influence of boys; rather, gendered patterns in subject choice persist because of stereotypical influences in society at large (Francis et al., 2003).

There is evidence to demonstrate that students who are aware of the material gain of having a science qualification are more like to continue with science in further and higher education (e.g. Tai et al., 2006) though the relationship between choice and the lower prevalence of girls in post-16 education and science-related careers is complex. The gender gap in science participation has been associated with family influences (e.g. Eccles, 1994), social class differences (e.g. Aschbacher et al., 2010) and socially embedded influences (e.g. Archer et al., in press a). Archer et al. (in press a) concluded that 'children's aspirations and views of science careers are formed within families, and these families play an important, albeit complex, role in shaping the boundaries and nature of what children can conceive of as possible and desirable and the likelihood of their being able to achieve these aspirations' (page 22). In this study we examine the role of the school in shaping or supporting aspirations to continue with physics after the age of 16.

\section{Methods}

The findings within this paper are derived from the quantitative analysis of year 10 physics data from UPMAP (Understanding Participation Rates in post-16 Mathematics And Physics), a longitudinal mixed methods project exploring post-16 mathematics and physics choices 
(Reiss et al., 2011). The year 10 physics UPMAP survey (with students who are 15 years old) used a variety of analytical approaches to identify the range of factors (individual, school and home) and their interactions with one another that influence intended participation in physics. We surveyed year 10 students as learners of physics in the academic year 2008 - 2009 and the analyses within this paper are based on data derived from 5034 students in 137 schools in England. We intentionally over-sampled schools that were above average in either or both of mathematics and physics attainment and post-16 participation, and within the schools we focused on students who were thought by their teachers to be on target to get grades $A *-D$ (i.e. above average or average grades) in GCSE in mathematics and physics/science. When we asked students about their experiences in their physics lessons and of their physics teachers we were also aware that some students would be taught physics in combined science classes. Therefore, we provided instructions for students, when completing this survey, only to think about their physics lessons and about science teachers who taught them physics.

Our survey took on board criticisms (e.g. Gardner, 1996) about the lack of clarity in science education research with respect to differentiating between different aspects of attitudes (e.g. distinguishing attitudes to teachers from attitudes to lessons). In addition, science education research often researches physics issues by subsuming measurements into research on science issues. Given the differences between the various sciences (e.g. after the age of 16, girls in England are more likely than boys to study biology but less likely to study physics) this is not a precise method to explore physics issues. Our research overcame this problem via the design of the physics year 10 survey which contained around 130 physicsspecific items rather than more general science-related items.

Why we use items within our analyses rather than constructs

Although in this paper we do not use construct-based analyses, elsewhere we have explored the underlying dimensions of the physics 10 surveys using factor analysis on constructs (aggregates of items) and then reliability analyses (using Cronbach's alpha) to confirm the underlying dimensions of the physics constructs prior to conducting any bi-variate or multivariate analyses. We have aggregated our survey items into a number of physics-specific constructs (via the use of factor analyses and reliability analyses): home support for achievement in physics; perceptions of physics teachers; emotional response to physics lessons; perceptions of physics lessons; physics self-concept; advice-pressure to study physics; social support in physics learning; and home support in physics learning. All constructs were found to have fair to high reliability (.6-.9).

Findings from other parts of the UPMAP project found that some girls had similar aspirations as some boys in continuing with physics post-16 (Mujtaba \& Reiss, in press). High aspiring students regardless of gender also expressed similar views about aspects of their physics education; for instance, they had similar levels of physics extrinsic material gain motivation. However, there were still key gender differences with regards to the physics education of such students, e.g. their perceptions of physics, their perceptions of physics teachers, support for learning in physics and encouragement to continue with physics post-16 (girls were at a disadvantage regardless of their high aspirations). The use of constructs did not help shed any light about what it was about their teachers, their physics lessons or physics itself that these girls had less positive perceptions about (despite their high aspirations). We also felt it was important to know the answer to this as there were a core group of girls who had low aspirations to continue with physics post-16 and were the group with the least positive perceptions of their physics education. In this paper we investigate what it is about perceptions of physics, physics lessons and the students' physics teachers that creates gender differences and which of these are most correlated with intended participation in post-16 physics. In addition, the UPMAP construct-based analysis to explore choice indicated that the 
construct 'perceptions of physics teachers' was not statistically significant once we controlled for students self-concept, extrinsic material gain motivation and advice-pressure to study physics. Triangulating findings with UPMAP's qualitative work (e.g. Rodd et al., 2010) indicated that there was a possibility that our construct-based multi-level analyses missed important points surrounding perceptions of physics, physics lessons and the students' teachers. This led to the focus of this paper, to explore issues at item level in.

All of the items were scored so that a high score represents strong agreement (items were on a 6-point Likert scale), with scores above three indicating positive responses / high agreements with statements. The key output variable of interest within our analyses was an item that asked students to rank on a scale that ranged from highly disagree (score of 1) to highly agree (score of 6) whether they were intending to continue with physics post-16. A score of 4 and above indicates an intention to participate, a score of 3 and below indicates an intention to not continue with physics post-16. The percentage response to each category is shown in Table 1 for all students as well as a breakdown by gender.

This paper examines which of the items from within the UPMAP surveys are most important in explaining intended post-16 physics participation amongst year 10 students whilst also determining which aspects of students' views of physics, physics lessons and physics teachers have a statistically significant gender imbalance, with possible implications for girls' post-16 physics participation. We explore these issues via bi-variate analyses (ttests) to explore the relationships between students' perceptions of physics teachers, physics lessons and physics (by exploring the individual items rather than the constructs) that were the most important in explaining differences between girls and boys, followed by correlation analyses (Pearson Product Moment) to explore which items (within each of these particular constructs) were most closely correlated with intention to participate in physics post-16. In addition a focus on gender differences within the t-tests was informed by construct-based multi-level modelling findings (Mujtaba et al., 2010) - the influence of gender remained important within the final models despite most other student background factors losing significance, thus we have continued to explore issues around gender within this paper. All of the findings reported in this paper are statistically significant at a minimum of $p<0.05$ (2tailed).

\section{Results}

\section{Students'perceptions of their physics teachers}

There were three clusters of items that explored issues with teachers: encouragement, relationships and competence. Students (as a group) on the whole had positive perceptions of their teachers. Table 2 shows students were most positive about their teachers really wanting them to understand physics (mean of 4.93), followed by teachers believing that all students can learn physics (mean of 4.90). Students were least positive about their physics teachers being interested in them as people (3.33) and liking all students (mean 3.80). All of the items are included in Table 2 which also shows the breakdown by gender and whether gender differences were statistically significant - six of the fifteen items indicated statistically significant differences between boys and girls. The largest effect size in gender differences was for ' $m y$ teacher thinks that I should continue with physics post-16' (ES=.337) followed by 'my teacher is good at explaining physics' (ES=.237). There was a small effect size of gender in the item 'my teacher has high expectations of what students can learn' (ES=.143). Three of the items where there were significant gender differences had an effect size of less than .100: 'my teacher is interested in me as a person', 'my teacher marks and returns homework quickly' and 'my teacher wants us to really understand physics'.

Teachers' encouragement: Boys were more likely to give positive responses about 
feeling that their teachers: encouraged them to continue with physics post-16 $(\mathrm{t}=8.47$, $\mathrm{p}<.001)$; had high expectations of what students can learn $(\mathrm{t}=4.634, \mathrm{p}<.001)$.

Personal relationships with physics teachers: Boys were more likely to report that their physics teachers were interested in them as people $(\mathrm{t}=2.839, \mathrm{p}<.001)$.

Competence of physics teachers: Boys were more likely to report that their physics teachers: were good at explaining physics $(\mathrm{t}=7.840, \mathrm{p}<.001)$; marked and returned homework quickly $(\mathrm{t}=2.596, \mathrm{p}<.01)$.

There were no statistically significant differences between girls and boys in their responses towards: teachers being interested in what students think; liking their physics teachers; teachers setting homework; their teachers believing all students can learn; their teachers do not let them get away with doing homework; teachers liking all students; teacher treats all students the same way regardless of their ability; their teachers caring about all students regardless of who gets good marks; teachers treating all students the same regardless of ability. It appears the most important issue with respect to explaining gender differences in perceptions of physics teachers is to do with teachers' encouragement and how the teachers explain physics.

\section{Intention to participate and perceptions of teachers}

A correlation analysis was conducted between the items that explored students' perceptions of their teachers and students' intentions to participate in physics after the age of 16 (see Table 2). The correlation analyses demonstrate that students' perceptions of their teachers personally encouraging them to continue with physics post-16 are more strongly associated with intended participation than are issues such as those to do with homework (e.g. my teacher does not let us get away with not doing homework; my physics teacher sets us homework). The two strongest associations between intended participation and items about teachers is the item that asks whether students think their teachers want them to study physics post-16 followed by teachers being good at explaining physics - in line with the two items that have the strongest gender effect size. The association ('teacher thinks that I should continue with physics post-16' with student's intended participation) is set apart from the rest as it correlated with medium strength whereas the others are weakly correlated. The four strongest correlations between students' perceptions of their teachers and their intention to continue with physics post-16 were: 'my teacher thinks I should continue to study physics after the age of sixteen' (.493); 'my physics teacher is good at explaining physics' (.256); 'I like my physics teacher' (.226) and 'my physics teacher is interested in me as a person' (.214).

\section{Students'perceptions of their physics lessons}

There were four clusters of items that explored issues with physics lessons: laboratory and practical work; learning physics concepts; enjoyment of physics lessons; self-concept in physics as impacted by physics lessons. All of the items are included in Table 3 which also shows the breakdown by gender and whether gender differences were statistically significant.

Descriptive statistics indicated that students on the whole had positive perceptions of their physics lessons but with some areas of concern. Collectively, boys and girls were most positive about looking forward to spending time in the laboratory doing experiments (mean of 4.11). They were least positive about looking forward to physics classes (3.14). For some of the items in Table 3 there were statistically significant differences in responses between boys and girls, with boys responding more positively to questions around physics lessons. The largest significant difference in responses between boys and girls was 'thinking about your physics lessons, how do you feel you compare with the others in your group?' 
( $E S=.554)$, followed by 'I do well in physics tests' $(E S=.474)$. Another notable finding was that all of the items that focused on perceptions of physics lessons had a significant effect size (in contrast to the findings on the items looking into perceptions of physics teachers, shown in Table 2) and that these effect sizes were generally larger than those found for the items that explored perceptions of physics teachers. The two effect sizes already noted above were followed by 'I look forward to spending time in the laboratory to do practical investigations $(\mathrm{ES}=.394)$, I enjoy my physics classes $(\mathrm{ES}=.367)$ and I look forward to physics classes $(E S=.346)$ - which were all larger than the largest effect size in Table 2: "my teacher thinks that I should continue with physics post-16' $(\mathrm{ES}=.337)$. There was only one item which had an effect size smaller than .100 in Table 3: 'in my lessons we do investigations to test our own ideas'. We found that amongst the perceptions of teacher items, 'my teacher is good at explaining physics' (ES=.237) had an effect size in line with an item clustered within lessons: 'my teacher explains how a physics idea can be applied to a number of different situations' $(E S=.265)$. These findings emphasise how important it is for teachers to explain physics in a way that engages girls and not alienate them from learning and understanding physics.

Laboratory and practical work: Boys were more positive about: looking forward to spending time in the laboratory doing practical investigations $(\mathrm{t}=13.062, \mathrm{p}<.001)$; having the opportunities to do investigations to test out their own ideas $(\mathrm{t}=2.089, \mathrm{p}<.001)$.

Learning physics concepts: Boys were: more likely to report that their teacher explained how physics ideas can be applied to a number of different situations $(t=8.969$, $\mathrm{p}<.001)$; more positive about having the opportunity to discuss their ideas about physics $(\mathrm{t}=6.860, \mathrm{p}<.001)$; more likely to report seeing the relevance of physics lessons $(\mathrm{t}=10.739$, $\mathrm{p}<.001)$.

Enjoyment of physics lessons: Boys were more likely to report: looking forward to their physics classes $(\mathrm{t}=11.753, \mathrm{p}<.001)$; enjoying their physics lessons $(\mathrm{t}=12.499, \mathrm{p}<.001)$.

Self concept in physics as impacted by physics lessons: Boys were: more positive about doing well in their physics tests $(\mathrm{t}=16.166, \mathrm{p}<.001)$; more likely to report doing better in their physics lessons than their peers $(\mathrm{t}=18.672, \mathrm{p}<.001)$.

\section{Intention to participate and perceptions of physics lessons}

These correlation analyses demonstrate that students' intrinsic valuation of lessons, which includes how relevant physics lessons are to their lives, is more strongly associated with intended participation than factors to do with discussing ideas, doing experiments and knowing how well they are doing in physics (see Table 3). That is not to say these factors are unimportant, but for intention to participate in physics, getting students intrinsically motivated seems to be more important. The three strongest associations between intended post-16 participation and perceptions of physics lessons were for: 'I look forward to physics classes' ( $\mathrm{r}=.494)$; 'I enjoy my physics lessons' $(\mathrm{r}=.475)$; and 'I can see the relevance of physics lessons' $(\mathrm{r}=.423)$. Cross relating these findings with those that looked into gender differences, the data highlight that 'I look forward to physics classes' revealed a significant difference between the genders $(\mathrm{ES}=.346)$ as well as being the item that was most highly correlated with intention for students, whether male or female, to participate in physics post16. The item which had the smallest association with intended participation was 'I don't find it difficult to apply most physics concepts to everyday problems' $(\mathrm{ES}=.144)$. Referring back to the findings around perceptions of teachers, these analyses continue to indicate that unfortunately the issues that are most important/correlated with intended participation in physics post-16 are also those that have the largest effect sizes in explaining differences between boys' and girls' perceptions of their physics education. 


\section{Students'perceptions of physics}

Items explored six areas concerning students' perceptions of physics: laboratory and practical work; usefulness of physics (a part of the extrinsic material gain and social gain constructs); self-concept in physics; liking of physics; physics and social skills; and doing physics. Descriptive statistics (Table 4) indicated that students' responses about physics were generally positive though there were some aspects of physics that they were not positive about / did not agree with. Students were most positive about / in agreement with 'to be good at physics, you need to work hard' (mean 4.66) and least positive about 'being good at physics makes you popular' (mean 1.95). For some of the items in Table 4 there were statistically significant differences in responses between boys and girls, with boys responding more positively to questions about physics. The largest significant difference in responses between boys and girls was for the item 'I am good at physics' $(\mathrm{ES}=.583)$, followed by 'I don't need help in physics' (ES=.548), followed by 'when I am doing physics, I always know what I am doing' (ES=.536). We note that overall these are the strongest effect sizes reported with respect to explaining differences between girls' and boys' perceptions of their physics education (when including perceptions of physics teachers and physics lessons). The next four strongest effect sizes (ranging from .347 to .411) were still larger than the effect sizes found for any of the perception of teacher items: 'I think physics will help me in the job I want to do in the future'; 'to be good at physics you need to be creative'; 'physics is interesting' and 'I think physics is an interesting subject'. There were three items which had significant gender difference effect sizes of less than .100: 'these days everybody needs to know some physics'; 'when I am doing physics I do not get upset'; and 'those who are good at physics are clever'. There were three items for which no statistically significant gender differences were found: 'being good at physics impresses people'; 'to be good at physics, you need to work hard'; and 'there is more than one right way to solve physics problems'.

Usefulness of physics: boys were more likely to report that: physics is a useful subject $(\mathrm{t}=9.483, \mathrm{p}<.001)$; physics is more likely to help them get into jobs they want to do in the future ( $\mathrm{t}=11.694, \mathrm{p}<.001)$; physics teaches individuals to think logically $(\mathrm{t}=5.138, \mathrm{p}<.001)$; physics helps individuals to solve everyday problems $(\mathrm{t}=6.572, \mathrm{p}<.001)$; physics is important in making new discoveries $(\mathrm{t}=5.181, \mathrm{p}<.001)$; people who are good at physics get well paid jobs, $(\mathrm{t}=5.640, \mathrm{p}<.001)$.

Self concept in physics: Boys were more likely to report that they: are good at physics $(\mathrm{t}=19.866, \mathrm{p}<.001)$; do not need help with physics $(\mathrm{t}=18.447, \mathrm{p}<.001)$.

Liking of physics: Boys were more likely to report that: physics is an interesting subject ( $\mathrm{t}=13.911, \mathrm{p}<.001)$; they find physics interesting $(\mathrm{t}=13.415, \mathrm{p}<.001)$; these days everyone needs to know some physics $(\mathrm{t}=2.070, \mathrm{p}<.05)$; it is interesting to find out about the laws of physics that explain different phenomena $(\mathrm{t}=8.622, \mathrm{p}<.001)$; physics is a useful subject $(\mathrm{t}=9.843, \mathrm{p}<.001)$.

Physics and social skills: Boys were more likely to report that physics: makes individuals popular $(\mathrm{t}=6.122, \mathrm{p}<.001)$.

Doing physics: Boys were more likely to report that: to be good at physics individuals need to be creative $(\mathrm{t}=12.043, \mathrm{p}<.001)$; those who are good at physics are those who are clever $(t=3.131, p<.001)$. Interestingly, girls were more likely to report that there is only one right way to solve any physics problem $(\mathrm{t}=1.488, \mathrm{p}<.01)$, which is in line with certain of the findings around physics. Girls, as a group, typically feel disengaged from physics and this may be related to the way it is taught, with girls not feeling there are a range of ways to learn physics.

Correlations between perceptions of physics and intended participation in physics

A correlation analysis was conducted between the items that explored students' perceptions 
of physics and their intention to participate in it post-16. Table 4 demonstrates that for the sample as a whole the three strongest associations between intended participation and perceptions of physics were for the items: 'I think physics will help me in the job I want to do in the future' (a part of the 'extrinsic material gain motivation' construct) (.674) - with the associated effect size for gender difference being .347; 'I think physics is an interesting subject' (.564) - with the associated effect size for gender difference being .411; 'I think physics is a useful subject' (a part of the 'extrinsic material gain motivation' construct) (.547) - with the associated effect size for gender difference being .287. In Mujtaba and Reiss (in press) we find that boys and girls who intended to continue with physics post-16 had similar levels of 'extrinsic material gain motivation' - though differed in other perceptions of their physics education. The correlations between items measuring extrinsic material gain motivation and intended participation in physics are not surprising; despite two of the items from the 'extrinsic material gain construct' being the most strongly associated items with intended participation, the gender differences are not as strong as those found in other areas of students' perceptions of their physics education.

\section{Discussion}

The findings within this paper help elucidate what it is about physics teachers, physics lessons and the subject itself that explains intended participation in physics post-16 both overall and for boys and girls considered separately. Previously, we have used factor analysis and construct work on our surveys in order to explore issues around physics education and participation (Mujtaba \& Reiss, in press). However, we found that the use of constructs masked the effect of individual items and did not clearly indicate what it was about experiences of physics education that explained gender differences in perceptions. Our findings using constructs indicated that after controlling for a range of psychological, motivation and attitudinal constructs, the construct that measured 'perceptions of physics teachers' lost significance and the construct most important in explaining intended participation was 'extrinsic material gain motivation' which measures what benefits, such as a good career, students believed they would receive for studying physics post-16 - and this finding still held true when analysis was undertaken at the level of items.

Within this paper, the item-based correlation analysis showed that amongst the 'perception of physics teachers' items, teachers' encouragement of individual students to continue with physics post-16 was the item that associated most strongly with intended participation whereas the remaining items exploring perceptions of physics teachers were only, at best, weakly correlated with intended participation. In addition, only six of the fifteen items within the 'perceptions of physics teachers' cluster revealed statistically significant differences between boys and girls. The largest effect size in gender difference of the fifteen items was for 'my teacher thinks that I should continue with physics post-16' $(\mathrm{ES}=.337)$ and this item was also the one most highly correlated with intention to continue with physics post-16 (.493). A similar pattern arose with the item for students' perceptions as to how well teachers explain physics (second largest association with intended participation in physics as well as the second largest effect size in gender differences). These gender differences were in favour of boys.

As Table 2 indicates, our survey explored a range of areas around what students think about their physics teachers and it is interesting that these two particular issues are prominent ones. Our work reported elsewhere (Mujtaba et al., 2010) did not find an influence of 'perceptions of teachers' construct and it is now clear why that was. Future studies ought to create construct measures that separate out issues to do with teacher encouragement to study 
physics post-16 from students' perceptions of teacher support and fairness and liking teachers as individuals. Within England's education and political context there seems to be a resigned acceptance that girls are less likely to continue with physics post-16. However, within our sample, girls report receiving less encouragement to continue with physics post-16 than boys, findings that concur with those of others (e.g. Archer et al., in press a).

With respect to items that tap into perceptions of physics lessons, the largest significant difference in responses between boys and girls was 'thinking about your physics lessons, how do you feel you compare with the others in your group?' ( $\mathrm{ES}=.554)$, followed by 'I do well in physics tests' (ES=.474). These findings demonstrate, as might be expected, that boys have higher self-confidence in their own performance than girls. Despite not all items within the perceptions of teachers cluster showing differences between boys and girls, all items that explored perceptions of physics lessons did. The effect sizes for a fair number of items within the perceptions of physics lessons cluster were substantially larger than for the items that explored perceptions of teachers, demonstrating that important differences between boys and girls are more likely to occur with respect to perceptions of their physics lessons than their physics teachers.

Our work highlights how important it is for teachers to teach physics in a way that engages girls and encourages their learning and development. Boys were significantly more positive: about having opportunities to explore, discuss and test their ideas in class; in their perceptions about how teachers helped them learn physics; in how much they looked forward to and enjoyed their physics classes; and were more confident about their ability in tests. Overall, students' intrinsic valuation of lessons is more strongly associated with intended participation than are factors to do with discussing ideas, doing experiments and knowing how well they are doing in physics. Table 3 shows that the correlation between intended participation and 'I look forward to physics classes' was .494, the highest association within this cluster of items; in addition, this item revealed a significant difference between the genders $(E S=.346)$. We suggest that there should be a greater focus on and recognition of girls' problematic educational experiences as reported by others (e.g. Paechter, 1998; Francis, 1999; Francis \& Skelton, 2005; Archer \& Francis, 2007).

In our construct-based work reported elsewhere (Mujtaba \& Reiss, under review) we found that the 'extrinsic material gain motivation' construct was the most important measure of a range of measures we tested (e.g. psychological, attitudinal, support, perceptions and motivations) in explaining intended participation - and this finding still held true within the item-based analyses reported here. Moreover, the work here pinpoints what it is specifically about 'extrinsic material gain motivation' that is related to intended participation. The analyses on the perceptions of teachers and lessons items highlight that the issues that are most important/correlated with intended participation in physics post-16 are also those that have the largest effect size in explaining differences between boys' and girls' perceptions of their physics education; however, this is not the case for the perception of physics items. Our work indicates that across all students the three strongest associations between intended participation and perceptions of physics were for the items: 'I think physics will help me in the job I want to do in the future', a part of our original 'extrinsic material gain motivation' construct $(\mathrm{r}=.674)$; 'I think physics is an interesting subject', a part of the original intrinsic value construct $(\mathrm{r}=.564)$ and 'I think physics is a useful subject' $(\mathrm{r}=.547)$, also a part of our original 'extrinsic material gain motivation' construct. In addition, we find that of all the items explored within this paper (perceptions of teachers, lessons and physics itself) these three items are the most strongly associated with intended participation - findings that mirror our construct-based analyses. Given there is a small gender difference (in favour of boys) in the recognition of the importance of 'physics extrinsic material gain motivation', we suggest that schools (as well as national policy) do more to reduce these inequalities in information 
and awareness. There is no reason why girls should not be as aware as boys of the importance of having a physics qualification and how that will relate to future careers.

The take home message of this research is that to boost post- 16 physics participation a particular focus needs to be placed on encouraging the development of students' extrinsic material gain motivation in both girls and boys by creating an awareness of the tangible benefits of having post-16 physics qualification. The physics-specific items that measure extrinsic material gain motivation are more tightly related to intention to study physics post16 than are any of the other items explored within this paper though the gender differences within these measures are not as large as for other items such those to do with self-concept, teacher encouragement and the intrinsic value of physics. Such findings part support and part challenge the findings of Hazari et al. (2010) and Bøe et al. (2011), both of which indicate that issues that make STEM careers attractive to boys, such as high pay, high status and the ability to control others, are less attractive for girls. Our own work using construct-based analyses did not find a difference between the extrinsic material gain motivation of a subset of girls and boys who intended to continue with physics (see Mujtaba and Reiss, in press) and in this paper we find that other areas of perceptions of physics education have larger effect sizes and possibly play a more important role in explaining gender differences.

We also emphasise the importance of teachers encouraging students to continue with physics post-16. This is also particularly important in highlighting gender differences in perception of teachers, suggesting that despite girls and boys having similar perceptions of their physics teachers with respect to homework issues, liking their teachers, fairness of teachers and emphasis on learning there is still a significant gender difference in students' perceptions with girls being less likely than boys to report that they are encouraged to continue with physics post-16. Such findings confirm that despite a shift away from gender stereotypical attitudes in career choices these still remain and that gendered patterns in subject choice persist (cf. Francis et al., 2003); perhaps more worryingly, stereotypical influences come to play with the direct interactions our students have with their physics teachers. Research demonstrates that teaching students to set themselves goals enhances their academic achievement, cognitive efficacy and intrinsic interest in subjects (Bandura \& Schunk, 1981; Skunk, 1989). Similarly, Reiss (2004) found teacher influence to be paramount to students liking of science subjects.

It is important to make physics an enjoyable subject for all students to study regardless of whether it is envisaged that they will or will not continue with the subject post16. In line with other research, e.g. Osborne and Collins (2001) and Reid (2003), our findings show that girls are significantly less likely to enjoy their physics/science lessons than are boys, feel they are less able to discuss and experiment with ideas, more likely to feel bored, not pay attention in class, find physics less interesting and feel less confident (have a lower self-concept in physics). Such issues indicate that there is a problem with how some teachers engage girls given that girls also report that, despite liking their physics teachers as much as boys do, these teachers have, on average, lower expectations of what they can learn, are less interested in them as people, are less good at explaining physics to them, are less likely really to want them to understand physics and are less likely to explain how physics is applicable to different situations. It is clear from our work and that of others that teaching styles disengage some girls. A possible way to overcome this would be to have more context-based curricula, pedagogies that allow for greater student involvement and voice and assessments that allow for greater student autonomy and creativity (Reiss, 2009).

Finally, we note that Miller et al. (2006) found that female high school students perceived scientists to be isolated, with little time for a social life, and saw the work of a scientist as having little relevance for social problems. Our own work demonstrates that such issues may be relevant; for example, we found that girls were less likely to think that physics 
improved social skills or was important in solving everyday problems. Overall, it seems that issues around girls' experiences of their physics education, inequalities in the educational experiences that girls have and the extent to which girls often do not feel a part of physics learning culture are crucial matters to which policy, research and practice should attend.

\section{Acknowledgements}

We are grateful to the Economic Social Research Council for funding the UPMAP project (RES-179-25-0013) from 2008-2011. We would also like to thank the schools and students who took part in this project, without whom the study would not have been possible, the UPMAP Advisory Group and the other members of the UPMAP Project.

\section{References}

Archer, L., \& Francis, B. (2006). Challenging classes? Exploring the role of social class within the identities and achievement of British Chinese pupils. Sociology, 40(1), 2949.

Archer, L., \& Francis, B. (2007). Understanding Minority Ethnic Achievement. London: Routledge.

Archer, L., Halsall, A., \& Hollingworth, S. (2007). Class, gender, (hetero) sexuality and schooling: paradoxes within working class girls' engagement with education and post16 aspirations. British Journal of Sociology of Education, 28(2), 165-180.

Archer, L., Halsall, A., \& Hollingworth, S. (2007). Inner-city feminities and education: 'race', class, gender and schooling in young women's lives. Gender and Education, 19(5), 549-568.

Archer, L., DeWitt, J., Osborne, J., Willis, B and Wong, B. (in press a). 'Balancing Acts': Elementary school girls' negotiations of femininity, achievement and science. International Journal of Science Education.

Archer, L., DeWitt, J., Osborne, J., Willis, B and Wong, B. (in press b). 'Not girly, not sexy, not glamorous': primary school girls' and parents' constructions of science aspirations. Pedagogy, Culture and Society.

Aschbacher, P. R., Li, E., \& Roth, E. J. (2010). Is science me? High school students' identities, participation and aspirations in science, engineering, and medicine. Journal of Research in Science Teaching, 47(5), 564-582.

Bandura, A., \& Schunk, D. H. (1981). Cultivating competence, self-efficacy, and intrinsic interest through proximal self-motivation. Journal of Personality and Social Psychology, 41(3), 586-598.

Bøe, M. V., Henriksen, E. K., Lyons, T., \& Schreiner, C. (2011). Participation in science and technology: young people's achievement-related choices in late-modern societies. Studies in Science Education, 47(1), 37-72.

Buck, G. A. (2002). Teaching discourses: Science teachers' responses to the voices of adolescent girls. Learning Environments Research, 5(1), 29-50.

Department for Education (2012). The Equality Act, 2010. Retrieved July 14, 2012, from http://www.education.gov.uk/aboutdfe/policiesandprocedures/equalityanddiversity/a0 064570/the-equality-act-2010.

Eccles, J. S. (1994). Understanding women's educational and occupational choices: applying the Eccles et al. model of achievement-related choices. Psychology of Women Quarterly, 18(4), 585-609.

Francis, B. (1999). Lads, lasses and (New) Labour: 14-16 year old students' responses to the 'laddish behaviour and boys' underachievement' debate. British Journal of Sociology of Education, 20(3), 357-373. 
Francis, B. (2000a). Boys, Girls and Achievement: Addressing the classroom issues. London: Routledge-Falmer.

Francis, B. (2000b). The gendered subject: students' gendered subject preferences and discussions of gender and subject ability. Oxford Review of Education, 26(1), 35-48.

Francis, B. (2002). Is the future really female? The impact and implications of gender for 1416 year olds' career choices. Journal of Education and Work, 15(1), 75-88.

Francis, B., \& Skelton, C. (2005). Reassessing Gender and Achievement. London: Routledge.

Francis, B., Hutchings, M., Archer, L., \& Melling, L. (2003). Subject choice and occupational aspirations among pupils at girls' schools. Pedagogy, Culture \& Society, 11(3), 425-442.

Gardner, P. L. (1975). Attitudes to science. Studies in Science Education, 2, 1-41.

Greenfield, T. (1996). Gender, ethnicity, science achievement, and attitudes. Journal of Research in Science Teaching, 33(8), 901-933.

Harding, S. (1991). Whose Science? Whose Knowledge? Milton Keynes: Open University Press.

Hazari, Z., Sonnert, G., Sadler, P. M. \& Shanahan, M.-C. (2010). Connecting high school physics experiences, outcome expectations, physics identity and physics career choice: a gender study. Journal of Research in Science Teaching, 47(8), 978-1003.

JCQ (2011a). Examination results: A-levels. Retrieved August 2, 2012, from http://www.jcq.org.uk/national_results/alevels/.pdf.

JCQ (2011b). Results: 2011. Retrieved August 2, 2012, from http://www.jcq.org.uk/attachments/published/1589/GCSE\%20RESULTS.pdf.

Mayberry, M. (1998). Reproductive and resistant pedagogies: the comparative roles of collaborative learning and feminist pedagogy in science education. Journal of Research in Science Teaching, 35(4), 443-449.

Miller, P., Blessing, J., \& Schwartz, S. (2006). Gender differences in high-school students' views about science. International Journal of Science Education, 28(4), 363-381.

Mujtaba, T., \& Reiss, M. J. (in press). What sort of girl wants to study physics after the age of 16 ? Findings from a large-scale UK survey. International Journal of Science Education.

Mujtaba, T., Hoyles, C., Reiss, M. J., Stylianidou, F., \& Riazi-Farzad, B., (2010). Mathematics and physics participation in the UK: Influences based on analysis of national survey results. British Educational Research Association (BERA) Annual Conference 2010, September 2010.

Murphy, C., \& Beggs, J. (2005). Primary science in the UK: A scoping study. Final report to the Wellcome Trust. London: Wellcome Trust.

Osborne, J. F., Simon, S., \& Collins, S. (2003). Attitudes towards science: A review of the literature and its implications. International Journal of Science Education, 25(9), 1049-1079.

Paechter, C. (1998). Educating the Other: Gender, Power and Schooling. London: Falmer.

Reid, N. (2003). Gender and physics. International Journal of Science Education, 25(4), 509536.

Reiss, M. J. (1993) Science Education for a Pluralist Society. Milton Keynes: Open University Press.

Reiss, M. J. (2004). Students' attitudes towards science: a long term perspective. Canadian Journal of Science, Mathematics and Technology Education, 4(1), 97-109.

Reiss, M. J. (2009). Assessing Ethics in Secondary Science: A Report of a Seminar held at the Nuffield Foundation. Retrieved March 18, 2012, from http://www.nuffieldbioethics.org/sites/default/files/files/Assessing\%20Ethics\%20in\% 20Secondary\%20Science.pdf. 
Reiss, M. J., Hoyles, C., Mujtaba, T., Riazi-Farzad, B., Rodd, M., Simon, S., \& Stylianidou, F. (2011). Understanding participation rates in post-16 mathematics and physics: conceptualising and operationalising the UPMAP Project. International Journal of Science and Mathematics Education, 9(2), 273-302.

Schunk, D. H. (1989). Social cognitive theory and self-regulated learning. In B. J. Zimmerman \& D. H. Schunk (Eds), Self-regulated Learning and Academic Achievement: Theory, research, and practice (pp. 83-110). New York: SpringerVerlag.

Spender, D. (1982). Invisible Women: The schooling scandal. London: Chameleon.

Tai, R. H., Qi Liu, C., Maltese, A. V., \& Fan, X. (2006). Planning early for careers in science. Science, 312(5777), 1143-1144. 
TABLE 1

Intention to participate in physics post-16 for year 10 students in England

\begin{tabular}{lrrrrrr}
\hline Percentage responses & $\begin{array}{r}\text { Strongly } \\
\text { disagree }\end{array}$ & Disagree & $\begin{array}{r}\text { Slightly } \\
\text { disagree }\end{array}$ & $\begin{array}{r}\text { Slightly } \\
\text { agree }\end{array}$ & $\begin{array}{r}\text { Agree } \\
\text { Strongly } \\
\text { agree }\end{array}$ \\
\hline Overall results for England sample & 21.4 & 23.7 & 13.1 & 18.9 & 14.0 & 8.8 \\
Boys & 17.7 & 18.1 & 12.7 & 19.5 & 18.7 & 13.3 \\
Girls & 24.9 & 28.7 & 13.6 & 18.4 & 9.9 & 4.5 \\
\hline
\end{tabular}


TABLE 2

Year 10 students' perceptions of their physics teachers

\begin{tabular}{|c|c|c|c|c|c|c|c|c|c|c|c|c|c|}
\hline \multirow{2}{*}{$\begin{array}{l}\text { Overall perceptions of physics teachers } \\
\text { Item }\end{array}$} & \multicolumn{4}{|c|}{$\dagger$ All students } & \multicolumn{3}{|c|}{ Boys } & \multicolumn{3}{|c|}{ Girls } & \multicolumn{3}{|c|}{ Comparison (boys and girls) } \\
\hline & $N$ & Corr. & $M$ & $S D$ & $N$ & $M$ & $S D$ & $N$ & $M$ & $S D$ & $t$ & $d f$ & $\begin{array}{l}\text { Effect size } \\
\text { Cohen's d }\end{array}$ \\
\hline $\begin{array}{l}\text { My teacher thinks that I should continue with } \\
\text { physics post-16 }\end{array}$ & 2537 & $0.493^{* * *}$ & 4.07 & 1.59 & 1222 & 4.34 & 1.49 & 1288 & 3.81 & 1.64 & 8.467 & 2502 & $0.337^{* * *}$ \\
\hline My teacher is good at explaining physics & 4430 & $0.256^{* * *}$ & 4.28 & 1.41 & 2027 & 4.46 & 1.36 & 2361 & 4.13 & 1.43 & 7.840 & 4338 & $0.237^{* * *}$ \\
\hline I like my physics teacher & 4646 & $0.226^{* *}$ & 4.03 & 1.53 & 2134 & 4.07 & 1.56 & 2466 & 4.00 & 1.50 & 1.508 & 4458 & $\mathrm{n} / \mathrm{s}$ \\
\hline My teacher is interested in me as a person & 3547 & $0.214^{* *}$ & 3.33 & 1.55 & 1623 & 3.40 & 1.57 & 1890 & 3.25 & 1.53 & 2.839 & 3402 & $0.096^{* *}$ \\
\hline My teacher is interested in what students think & 4241 & $0.191^{* *}$ & 4.26 & 1.35 & 1937 & 4.30 & 1.36 & 2265 & 4.22 & 1.34 & 1.932 & 4082 & $\mathrm{n} / \mathrm{s}$ \\
\hline $\begin{array}{l}\text { My teacher has high expectations of what students } \\
\text { can learn }\end{array}$ & 4244 & $0.188^{* *}$ & 4.83 & 1.07 & 1949 & 4.91 & 1.06 & 2257 & 4.75 & 1.07 & 4.634 & 4120 & $0.143^{* *}$ \\
\hline My teacher seems to like all the students & 4118 & $0.182^{* *}$ & 3.80 & 1.57 & 1883 & 3.80 & 1.58 & 2201 & 3.80 & 1.55 & 0.146 & 3956 & $\mathrm{n} / \mathrm{s}$ \\
\hline My teacher marks and returns homework quickly & 4151 & $0.179^{* *}$ & 4.05 & 1.47 & 1904 & 4.11 & 1.46 & 2209 & 3.99 & 1.48 & 2.596 & 4037 & $0.081^{* *}$ \\
\hline My teacher wants us to really understand physics & 4345 & $0.176^{* *}$ & 4.93 & 1.02 & 1996 & 4.96 & 1.03 & 2307 & 4.90 & 1.01 & 2.162 & 4183 & $0.066^{*}$ \\
\hline $\begin{array}{l}\text { My teacher believes that all students can learn } \\
\text { physics }\end{array}$ & 4225 & $0.163^{* *}$ & 4.90 & 1.03 & 1946 & 4.92 & 1.04 & 2238 & 4.89 & 1.02 & 0.860 & 4075 & $\mathrm{n} / \mathrm{s}$ \\
\hline $\begin{array}{l}\text { My teacher treats all students the same regardless } \\
\text { of their ability }\end{array}$ & 4246 & $0.156^{* *}$ & 4.36 & 1.38 & 1956 & 4.37 & 1.41 & 2250 & 4.36 & 1.35 & 0.132 & 4063 & $\mathrm{n} / \mathrm{s}$ \\
\hline $\begin{array}{l}\text { My teacher believes that mistakes are } \mathrm{OK} \text { when } \\
\text { learning }\end{array}$ & 4220 & $0.154^{* *}$ & 4.60 & 1.24 & 1955 & 4.58 & 1.26 & 2224 & 4.62 & 1.21 & 0.947 & 4063 & $\mathrm{n} / \mathrm{s}$ \\
\hline My physics teacher sets us homework & 4498 & $0.129^{* *}$ & 4.79 & 1.24 & 2053 & 4.81 & 1.24 & 2404 & 4.76 & 1.24 & 1.298 & 4350 & $\mathrm{n} / \mathrm{s}$ \\
\hline $\begin{array}{l}\text { My teacher does not only care about students who } \\
\text { get good marks }\end{array}$ & 4151 & $0.075^{* *}$ & 4.38 & 1.44 & 1881 & 4.36 & 1.50 & 2229 & 4.40 & 1.39 & 0.923 & 3883 & $\mathrm{n} / \mathrm{s}$ \\
\hline $\begin{array}{l}\text { My teacher does not let us get away with not doing } \\
\text { homework }\end{array}$ & 4321 & $0.050^{* *}$ & 4.55 & 1.39 & 1976 & 4.56 & 1.44 & 2304 & 4.54 & 1.35 & 0.350 & 4087 & $\mathrm{n} / \mathrm{s}$ \\
\hline
\end{tabular}

Notes: N (number); M (mean); SD (standard deviation); comparisons between girls and boys.

$\uparrow$ Shaded area is a separate set of analyses (correlations (Corr.)) between items that explore all students' perceptions of their teachers with students' intentions to continue to study physics post-

16 ; unshaded area explores gender issues amongst items; ** significant at .001; * significant at .01 . 
TABLE 3

Year 10 students' perceptions of their physics lessons

\begin{tabular}{|c|c|c|c|c|c|c|c|c|c|c|c|c|c|}
\hline \multirow{2}{*}{$\begin{array}{c}\text { Overall perceptions of physics lessons } \\
\text { Item }\end{array}$} & \multicolumn{4}{|c|}{ †All students } & \multicolumn{3}{|c|}{ Boys } & \multicolumn{3}{|c|}{ Girls } & \multicolumn{3}{|c|}{ Comparison (boys and girls) } \\
\hline & $N$ & $\sim$ Corr. & $M$ & $S D$ & $N$ & $M$ & $S D$ & $N$ & $M$ & $S D$ & $t$ & $d f$ & $\begin{array}{l}\text { Effect size } \\
\text { Cohen's a }\end{array}$ \\
\hline I look forward to physics classes & 4721 & $0.494^{* *}$ & 3.14 & 1.44 & 2171 & 3.40 & 1.46 & 2505 & 2.91 & 1.38 & 11.753 & 4489 & $0.346^{* * *}$ \\
\hline I enjoy my physics lessons & 4710 & $0.475^{* *}$ & 3.44 & 1.47 & 2166 & 3.72 & 1.45 & 2499 & 3.19 & 1.43 & 12.499 & 4547 & $0.367^{* * *}$ \\
\hline I can see the relevance of physics lessons & 4671 & $0.423^{* *}$ & 3.95 & 1.38 & 2148 & 4.18 & 1.33 & 2478 & 3.75 & 1.37 & 10.739 & 4566 & $0.316^{* * *}$ \\
\hline I do well in physics tests & 4693 & $0.385^{* *}$ & 3.84 & 1.33 & 2160 & 4.16 & 1.27 & 2488 & 3.55 & 1.31 & 16.166 & 4593 & $0.474^{* * *}$ \\
\hline $\begin{array}{l}\text { Thinking about your physics lessons, how do you } \\
\text { feel you compare with the others in your group? }\end{array}$ & 4632 & $0.323^{* *}$ & 3.32 & 1.09 & 2129 & 3.63 & 1.07 & 2456 & 3.05 & 1.04 & 18.672 & 4451 & $0.554^{* * *}$ \\
\hline $\begin{array}{l}\text { I look forward to spending time in the lab to do } \\
\text { practical investigations }\end{array}$ & 4424 & $0.298^{* *}$ & 4.11 & 1.59 & 2027 & 4.44 & 1.49 & 2353 & 3.83 & 1.61 & 13.062 & 4353 & $0.394^{* * *}$ \\
\hline $\begin{array}{l}\text { My teacher explains how a physics idea can be } \\
\text { applied to a number of different situations }\end{array}$ & 4664 & $0.289^{* *}$ & 3.84 & 1.38 & 2148 & 4.03 & 1.37 & 2471 & 3.67 & 1.36 & 8.969 & 4519 & $0.265^{* * *}$ \\
\hline $\begin{array}{l}\text { In my physics lessons, I have the opportunity to } \\
\text { discuss my ideas about physics }\end{array}$ & 4685 & $0.279^{* *}$ & 3.88 & 1.40 & 2157 & 4.03 & 1.38 & 2482 & 3.75 & 1.39 & 6.860 & 4560 & $0.202^{* * *}$ \\
\hline $\begin{array}{l}\text { In my lessons, we do investigations to test our own } \\
\text { ideas }\end{array}$ & 4394 & $0.214^{* *}$ & 3.46 & 1.48 & 2014 & 3.51 & 1.49 & 2337 & 3.42 & 1.46 & 2.089 & 4225 & $0.064^{*}$ \\
\hline $\begin{array}{l}\text { I don't find it difficult to apply most physics } \\
\text { concepts to everyday problems }\end{array}$ & 4680 & $0.039^{* *}$ & 3.50 & 1.39 & 2154 & 3.61 & 1.42 & 2480 & 3.41 & 1.35 & 4.874 & 4470 & $0.144^{* * *}$ \\
\hline
\end{tabular}

Notes: N (number); M (mean); SD (standard deviation); comparisons between girls and boys.

$\dagger$ Shaded area is a separate set of analyses (correlations (Corr.)) between items that explore all students' perceptions of their teachers with students' intentions to continue to study physics post-

16; unshaded area explores gender issues amongst items; ${ }^{* *}$ significant at $.001 ; *$ significant at .01 . 
TABLE 4

Year 10 students' perceptions of physics

\begin{tabular}{|c|c|c|c|c|c|c|c|c|c|c|c|c|c|}
\hline \multirow{2}{*}{$\begin{array}{c}\text { Overall perceptions of physics } \\
\text { Item }\end{array}$} & \multicolumn{4}{|c|}{$\dagger$ All students } & \multicolumn{3}{|c|}{ Boys } & \multicolumn{3}{|c|}{ Girls } & \multicolumn{3}{|c|}{ Comparison (boys and girls) } \\
\hline & $N$ & $\sim$ Corr. & $M$ & $S D$ & $N$ & $M$ & $S D$ & $N$ & $M$ & $S D$ & $t$ & $d f$ & $\begin{array}{l}\text { Effect size } \\
\text { Cohen's d }\end{array}$ \\
\hline $\begin{array}{l}\text { I think physics will help me in the job I want to do in } \\
\text { the future }\end{array}$ & 4681 & $0.674^{* *}$ & 3.06 & 1.60 & 2161 & 3.35 & 1.65 & 2472 & 2.80 & 1.50 & 11.694 & 4399 & $0.347^{* * *}$ \\
\hline Physics is interesting & 4692 & $0.564^{* *}$ & 3.60 & 1.53 & 2157 & 3.92 & 1.53 & 2494 & 3.32 & 1.48 & 13.415 & 4505 & $0.395^{* * *}$ \\
\hline I think physics is a useful subject & 4781 & $0.547^{* *}$ & 4.24 & 1.24 & 2205 & 4.43 & 1.25 & 2527 & 4.08 & 1.21 & 9.843 & 4605 & $0.287^{* * *}$ \\
\hline I think physics is an interesting subject & 4693 & $0.512^{* *}$ & 3.68 & 1.45 & 2159 & 3.99 & 1.46 & 2486 & 3.40 & 1.39 & 13.911 & 4484 & $0.411^{* * *}$ \\
\hline I am good at physics & 4675 & $0.465^{* *}$ & 3.85 & 1.31 & 2171 & 4.23 & 1.22 & 2456 & 3.50 & 1.28 & 19.866 & 4601 & $0.583^{* * *}$ \\
\hline $\begin{array}{l}\text { It's interesting to find out about the laws that explain } \\
\text { different phenomena }\end{array}$ & 3614 & $0.412^{* *}$ & 3.90 & 1.46 & 1730 & 4.12 & 1.41 & 1859 & 3.70 & 1.47 & 8.622 & 3584 & $0.288^{* * *}$ \\
\hline $\begin{array}{l}\text { When I am doing physics, I always know what I am } \\
\text { doing }\end{array}$ & 4720 & $0.409^{* *}$ & 3.21 & 1.31 & 2169 & 3.57 & 1.30 & 2504 & 2.89 & 1.23 & 18.204 & 4503 & $0.536^{* * *}$ \\
\hline Physics helps you in solving everyday problems & 4290 & $0.372^{* *}$ & 3.33 & 1.33 & 1977 & 3.47 & 1.37 & 2277 & 3.20 & 1.27 & 6.572 & 4067 & $0.203^{* * *}$ \\
\hline When I am doing physics, I am learning new skills & 4708 & $0.363^{* *}$ & 4.01 & 1.25 & 2163 & 4.18 & 1.24 & 2500 & 3.86 & 1.23 & 8.597 & 4551 & $0.253^{* * *}$ \\
\hline When I am doing physics, I pay attention & 4723 & $0.359^{* *}$ & 3.83 & 1.31 & 2169 & 4.01 & 1.31 & 2509 & 3.69 & 1.30 & 8.323 & 4569 & $0.244^{* * *}$ \\
\hline Physics teaches you to think logically & 4207 & $0.350^{* *}$ & 4.05 & 1.25 & 1936 & 4.16 & 1.29 & 2233 & 3.96 & 1.21 & 5.138 & 3992 & $0.160^{* * *}$ \\
\hline When I am doing physics, I am not bored & 4708 & $0.326^{* *}$ & 3.18 & 1.53 & 2160 & 3.42 & 1.56 & 2501 & 2.98 & 1.47 & 10.031 & 4474 & $0.296^{* * *}$ \\
\hline Physics improves your social skills & 4170 & $0.320^{*}$ & 2.19 & 1.21 & 1886 & 2.26 & 1.29 & 2251 & 2.12 & 1.12 & 3.596 & 3763 & $0.114^{* * *}$ \\
\hline Being good at physics impresses people & 4006 & $0.310^{* *}$ & 3.35 & 1.41 & 1817 & 3.39 & 1.44 & 2153 & 3.31 & 1.37 & 1.608 & 3789 & $\mathrm{n} / \mathrm{s}$ \\
\hline People who are good at physics get well-paid jobs & 3666 & $0.299^{* *}$ & 4.17 & 1.18 & 1713 & 4.28 & 1.17 & 1914 & 4.06 & 1.17 & 5.640 & 3576 & $0.188^{* * *}$ \\
\hline To be good at physics, you need to be creative & 4203 & $0.296^{* *}$ & 2.57 & 1.31 & 1905 & 2.83 & 1.39 & 2266 & 2.35 & 1.18 & 12.043 & 3738 & $0.380^{* * *}$ \\
\hline When I am doing physics, I don't daydream & 4707 & $0.274^{* *}$ & 3.26 & 1.58 & 2164 & 3.49 & 1.65 & 2496 & 3.06 & 1.49 & 9.288 & 4409 & $0.275^{* * *}$ \\
\hline These days, everybody needs to know some physics & 4301 & $0.267^{* *}$ & 3.95 & 1.26 & 1983 & 3.99 & 1.31 & 2285 & 3.91 & 1.22 & 2.070 & 4077 & $0.064^{*}$ \\
\hline Physics is important in making new discoveries & 4374 & $0.244^{* *}$ & 4.57 & 1.22 & 2025 & 4.67 & 1.20 & 2312 & 4.48 & 1.22 & 5.181 & 4276 & $0.158^{* * *}$ \\
\hline Being good at physics makes you popular & 4034 & $0.236^{* *}$ & 1.95 & 1.17 & 1834 & 2.07 & 1.27 & 2170 & 1.84 & 1.07 & 6.122 & 3590 & $0.197^{* * *}$ \\
\hline I don't need help with physics & 4668 & $0.233^{* *}$ & 3.39 & 1.52 & 2141 & 3.82 & 1.53 & 2481 & 3.01 & 1.40 & 18.447 & 4384 & $0.548^{* * *}$ \\
\hline Those who are good at physics are clever & 4238 & $0.141^{* *}$ & 4.07 & 1.40 & 1944 & 4.14 & 1.38 & 2257 & 4.01 & 1.41 & 3.131 & 4129 & $0.097^{* *}$ \\
\hline To be good at physics, you need to work hard & 4494 & $0.114^{* *}$ & 4.66 & 1.22 & 2052 & 4.69 & 1.22 & 2406 & 4.64 & 1.22 & 1.579 & 4348 & $\mathrm{n} / \mathrm{s}$ \\
\hline
\end{tabular}


There is more than one right way to solve physics problem

$3379 \quad 0.094^{* *} \quad 4.22 \quad 1.37 \quad 1612$

When I am doing physics, I do not get upset

Notes: N (number); M (mean); SD (standard deviation); comparisons between girls and boys

$\uparrow$ Shaded area is a separate set of analyses (correlations (Corr.)) between items that explore all students' perceptions of their teachers with students' intentions to continue to study physics post-

16 ; unshaded area explores gender issues amongst items; $* *$ significant at .001; * significant at .01 . 